\title{
Sonographic assessment of diaphragmatic function as a predictor for weaning from mechanical ventilation
}

Sherif Refaat Abdel Fattah (1), Radwa Ahmed Elhefny (2), Tamer sayed Abdel Mawla (3), Afnan Mahmoud Abd El Halim (4)

(1) Chest Departement, Faculty of medicine, Fayoum university.

(2) Chest Departement, Faculty of medicine, Fayoum university.

(3) Intensive cre unit, Faculty of medicine, Fayoum university.

(4) Chest Departement, Faculty of medicine, Fayoum university. Corresponding author: Dr: Afnan Mahmoud Abd EI Halim

E-mail: ama81@fayoum.edu.eg

Tel: 01068299696

Abstract:

\section{Introduction:}

Weaning from mechanical ventilation is an essential element in the care of ventilatory support patients in ICUs [1].

Weaning depends on the strength of respiratory muscles, the load applied to those muscles, and the respiratory drive to breathe [2].

Weaning failure in critically ill patients is known to be strongly associated with two risk factors, in particular as the presence of infection, sepsis and VIDD [3].

Ultrasonography is a promising technique for structural and functional evaluation of the diaphragm. [4].

\section{Aim of the study:}

Interretation of ventilator parameter with weaning outcome.

\section{Patients and methods:}

This study includes 30 patients who were admitted at ICU units and were invasively mechanically ventilated. All patients subjected to assessment of the weaning parameters (RSBI, TV, ABG readings, weaning time) with weaning outcome 
Results: Out of the 30 mechanically ventilated patients, $56.6 \%$ of the patients show successful weaning and, $43.3 \%$ of the patients show failed weaning. The mean value of tidal volume in successful weaning is $416.7 \pm 60.6 \mathrm{mml}$, while $226.7 \pm 45.8 \mathrm{mml}$ is in failed weaning group. The mean value of RSBI in successful weaning is $59.2 \pm$ $10.6 \mathrm{breath} / \mathrm{min} / \mathrm{L}$, while in failed weaning group is $104.2 \pm 18.4 \mathrm{breath} / \mathrm{min} / \mathrm{L}$.

Conclusion: interpretation of ventilator parameter can assess weaning outcome.

Keywords: Mechanical ventilation, weaning, ICU.

\section{Introduction:}

Weaning is the progressive decrease of the amount of support that a patient receives from the mechanical ventilator [2].

Many of mechanically ventilated patients fail their initial trial weaning from mechanical ventilation [5].
Most international weaning researchers have attempted to find better indexes or parameters which can assess the weaning outcome in the best possible way [6].

Ultrasound is an evolving technique that is now being used to image the diaphragm in normal and pathologic conditions given recent advances that allow high-resolution images [7].

\section{Subject and methods:}

The study was conducted in ICU department, Fayoum University hospital during 2018- 2019.

\section{Patient's selection:}

This study included 30 patients who were invasively mechanically ventilated and were admitted to the intensive care unit (ICU).

\section{Inclusion criteria:}

Selection of patients was based on the likelihood of being prolonged mechanically ventilated $(>48 \mathrm{~h})$. All the following data were collected for each patient.

\section{Exclusion criteria:}

Patients with age $<18$ years, history of neuromuscular disease, hemodynamic instability.

\section{Methods:}


Every person included in the study was submitted to the following medical procedure:

1: Complete history taking including:

I. Personal data: Name, Age, Sex

II. History of comorbidity: diabetes mellitus, hypertention and smoking

III. Cause of respiratory failure e.g: COPD, pneumonia, sepsis, ARDS, shock, cerebrovascular stroke and organ failure.

2: Complete physical examination:

General examination:

I. Vital signs (pulse, blood pressure, respiratory rate and body temperature)

II. Cardiovascular examination

III. Abdominal examination

Chest examination included:

I. Inspection for: chest shape and mobility.

II. Palpation for tenderness and position of the apex of the heart

III. Percussion for: impaired note, liver dullness.

IV. Auscultation for: breathe sounds and adventitious sounds.

3: Laboratory evaluation:
I. Arterial blood gases (at zero day of intubation, at weaning trial, after extubation and before discharge or referral to ward)

II. Routine investigation: (complete blood count $(\mathrm{CBC})$, sodium $(\mathrm{Na})$, potassium $(\mathrm{K})$, urea, creatinine, liver enzymes and coagulation profile).

4: Radiologically: X-ray chest done on admission and before weaning and CT chest was done when needed.

5: Modes of mechanical ventilation which is volume assisted control at start of ventilation and pressure support mode during weaning trial.

II. FIO2, tidal volume, respiratory rate, RSBI (respiratory rate/ tidal volume

(in liters)), PEEP, PEAK, I:E ratio, duration on ventilator before weaning (the time spent in volume controlled mode) and weaning time (the time spent receiving partial support including PS mode, corresponding to total ventilation time minus the full support period including VAC mode ).

6: All ICU patients who met the criteria to start weaning process.

As regards patients included in the study are divided into two groups according to their response to weaning trials: successful weaning, failed weaning group.

Assessment of weaning parameters (RSBI, $\mathrm{TV}$, weaning time, $\mathrm{ABG}$ ) during weaning to assess extubation outcome. 


\section{Statistical analysis of data:}

The collected data were organized, tabulated and statistically analyzed using SPSS software statistical computer package version 22 (SPSS Inc, USA). For quantitative data, the mean, standard deviation (SD) were calculated. An independent $\mathrm{t}$-test was used to test the differences between the two groups of patients (successful and failed weaning). For interpretation of the results of tests of significance, significance was adopted at $\mathrm{P} \leq$ 0.05 .

\section{Results:}

\section{Demographic characteristics of the study population:}

The study was conducted over 30 patients, their age range from $20-85$ years old with a mean \pm SD of $55.2 \pm 19$.

Risk factors in our study group: $20.0 \%$ of patients are diabetic, $23.3 \%$ are hypertensive and $43.3 \%$ are smokers as shown in table 1 .

Classification of patients in our study as regarding weaning outcome: Successful weaning group: which represent $17 / 30$ and failed weaning group: which represent 13/30 as shown in table 2

But there was no statistically significant difference in total cycle duration and inspiration duration during the weaning trial with p-value 0.202 and 0.526 respectively within the successful weaning group and failed weaning group as shown in table 3 .

There was a statistically significant difference between mean weaning time (days) in successful weaning and failed weaning as 3.6 days \pm 3 days vs 6 days \pm 3 days with $P$ value 0.041 . No significance difference between successful weaning and failed weaning in number of days on ventilator before weaning ( $p$ value 0.513 ) as shown in figure 1.

As regarding ventilator parameters:

TV: There was a statistically significant difference between patients with successful weaning and those with failed weaning during weaning trial as the mean value in successful weaning is $416.7 \pm 60.6 \mathrm{mml}$ while in failed weaning $226.7 \pm 45.8 \mathrm{mml}$ ( $\mathrm{P}$ value $<0.0001$ ) as shown in figure 2 .

RSBI: There was a statistically significant difference between patients with successful weaning and those with failed weaning during weaning trial as the mean value in successful weaning $59.2 \pm 10.6 \mathrm{breath} / \mathrm{min} / \mathrm{L}$ while in failed weaning $104.2 \pm 18.4$ breath $/ \mathrm{min} / \mathrm{L}$ (P value $<0.0001)$ as shown in figure 3 .

PEEP, FIO2, PEAK, I:E ratio, FIO2: There is no statistical significant difference between successful weaning and failed weaning group as shown in figure 4 .

In successful weaning group there was statistical significant difference between 
measues at start of intubation and weaning trial as regards PEAK, FIO2, TV, RSBI.

In failed weaing group there was no statistical significant difference between measues at start of intubation and weaning trial as regards PEAK, PEEP, I:E ratio. But, there was statistical significant difference between measues at start of intubation and weaning trial as regards TV, RSBI, FIO2.

The relation between successful weaning and failed weaning as regarding $\mathrm{ABG}$ :

PO2, HCO3, SO2, HR, RR: There was no a statistically significant difference between successful weaning and failed weaning group as shown in table.

PCO2: There was a statistically significant difference between successful weaning and failed weaning group as shown in figure 5.

\section{Discussion:}

Mechanical ventilation (MV) is a common life support strategy used in critically ill patients [3].

Weaning is the gradual liberation from MV to spontaneous breathing allowing the patient to breathe without mechanical support [8].

Respiratory pump insufficiency is probably the most common cause of weaning failure and may result in an imbalance between respiratory muscle workload and respiratory neuromuscular capability [9].
Mechanical ventilation is associated with decreased muscle weight and alterations in contractile properties of the diaphragm within 48 hours of intubation [10].

Ultrasound has become a diagnostic technique of emerging interest among clinicians and scientists [11].

In this study 30 patients who were invasively mechanically ventilated for more than are 48 hours, their age range from $20-$ 85 years old with a mean \pm SD of $55.2 \pm 19$

In our study we correlate between weaning parameter and weaning outcome.

In this study $56.6 \%$ of patients show successful weaning while $43.3 \%$ show failed weaning.

As regarding weaning time there was a statistically significant difference between mean weaning time in successful weaning and failed weaning group as $3.6 \pm 3$ days in successful weaning vs. $6 \pm 3$ days in failed weaning group with $\mathrm{P}$ value 0.04 . This result was in concordant with Horiana B et al 2012, (10 days vs. 22 days in failed weaning group), which show that long weaning time is associated with weaning failure. Unlikely, there is no significance difference between successful weaning and failed weaning group in number of days on ventilator before weaning trial ( $\mathrm{p}$ value 0.513 ) [12].

As regarding RSBI In our study there was a statistically significant difference between patients with successful weaning and those 
with failed weaning during weaning trial as the mean value in successful weaning was $59.2 \pm 10.6$ breath $/ \mathrm{min} / \mathrm{L}$ while in failed weaning $104.2 \pm 18.4$ breath $/ \mathrm{min} / \mathrm{L}$ (P value $<0.0001)$.

In concordant to Saeed A et al, 2016 found that average RSBI was 91 between patients with success weaning and became 123.6 between patients with failed weaning [13]. Disagree with Palkar A et al, 2018 who show that RSBI in successful weaning was $45.9 \pm 19.6$ breath $/ \mathrm{min} / \mathrm{L}$ and in failed weaning was $75.5 \pm 57 \mathrm{breath} / \mathrm{min} / \mathrm{L} \mathrm{[14]}$.

As regards $A B G$, there was no statistically significant difference between successful weaning and failed weaning group among $\mathrm{PH}$ (7.4) but within $\mathrm{PCO} 2$ there was a statistically significant difference between successful weaning $(48.1 \pm 10.7 \mathrm{mmHg})$ and failed weaning group $(37.3 \pm 6.9 \mathrm{mmHg})$ with $P$ value 0.005 . In controversy to Jaber et al 2008 which showed that PCO2 was higher in patients with diaphragm dysfunction and suspect weaning failure as hypercapnia and hypercapnic acidosis impair diaphragm contractility [15]. In concordant to our study, Akca $O$ et al., 2013 showed that mild to moderate levels of hypercapnia diminish the ventilator induced diaphragmatic inflammation [16]. As regards SO2 there was no a statistically significant difference between successful weaning and failed weaning group during weaning which is in controversy with Davis R et al 2012 who found that more hypoxia leads to formation of reactive oxygen species and associated with more weaning failure [17].

Conclusion: interpretation of ventilator parameter can assess weaning outcome. TV, RSBI, weaning time act as a good index to suspect weaning outcome.

\section{Reference:}

1: Lerolle N, Gue'rot E, Dimassi S, Zegdi R, Faisy C, Fagon JY, Diehl JL. Ultrasonographic diagnostic criterion for severe diaphragmatic dysfunction after cardiac surgery. Chest 2009;135(2):401-407.

2: M.D.Nizar Eskandar, Michael J. Apostolakos, Weaning from mechanical ventilation, Crit. Care Clin.2007; 23:263274

3: Supinski GS, Ann Callahan L. Diaphragm weakness in mechanically ventilated critically ill patients. Crit Care. 2013;17(3):R120.

4: Youssriah Y. Sabria, Sabah A.M. Husseinb, Ahmed A.M. Baza, et al. Ultrasonographic evaluation of the diaphragm. Egyptian Journal of Bronchology, 2019; 13: 690-698.

4: Gerscovich EO, Cronan M, McGahan JP, Jain K, Jones CD. Ultrasonographic 
evaluation of diaphragmatic motion. J Ultrasound Med, 2001; 20:597-604.

5: Magalhaes PA, Camillo CA, Langer D, Livia B, et al. Weaning failure and respiratory muscle function: What has been done and what can be improved? Respiratory medicine. 2018; 134: 54-61.

6: N. MacIntyre, D. Cook, E. Ely, et al, Evidence-based guidelines for weaning and discontinuing ventilatory support, Chest. 2001; 120(6):375-395.

7: Fedullo AJ, Lerner RM, Gibson J, Shayne DS. Sonographic measurement of diaphragmatic motion after coronary artery bypass surgery. Chest 1992;102:1683-1686.

8: Abu Youssef HA, Shalaby AO, Abd El Hafiz AM, Shaban M, et al. Predictive value of rapid shallow breathing index in relation to the weaning outcome in ICU patients. Egyptian Journal of Chest Diseases and Tuberculosis. 2016; 65: 465-472. 11

9: Jonkman AH, Jansen D and Heunks LM. Novel insights in ICU-acquired respiratory muscle dysfunction: implications for clinical care. Critical Care. 2017; 21(1): 64.

10: Capdevila X, Lopez S, Bernard N, Rabischong E, Ramonatxo M, Martinazzo $\mathrm{G}$, et al. Effects of controlled mechanical ventilation on respiratory muscle contractile properties in rabbits. Intensive Care Med 2003;29:103-110.

11: Haaksma M, Tuinman PR and Heunks L. Ultrasound to assess diaphragmatic function in the critically ill- a critical perspective. Annals of translational medicine. 2017; 5.

12: Horiana B, Grosu M, Young I, Rose $\mathrm{KM}$, et al. Diaphragm muscle thinning in patients who are mechanically ventilated, Chest 2012; 124(6): 1455-1460.

13: Saeed A, El Assal G, Ali TM, Hendawy M. Role of ultrasound in assessment of diaphragmatic function in chronic obstructive pulmonary disease patients during weaning from mechanical ventilation. Egyptian Journal of Bronchology, 2016; 10:167-72.

14: Palkar A, Mayo P, Singh K, Koenig S, Rivkah D, Harly G, et al. Serial Diaphragm Ultrasonography to Predict Successful Discontinuation of Mechanical Ventilation. Springer Science+Business Media, LLC, Lung 2018; 196:363-368.

15: Jaber S, Petrof B, Jung B, Matecki S, et al. Rapidly progressive diaphragmatic weakness and injury during mechanical ventilation in humans, Am. J. Respir. Crit. Care Med. 2011; 183: 364-371. 
16: Akca O and Bautista A. Hypercapnia and ventilator-induced diaphragmatic dysfunction. Critical Care. 2013; 17(2): 129.

17: Davis R, Bruells C, Stabley J, Behnke $\mathrm{BJ}$, et al. Mechanical ventilation reduces rat diaphragm blood flow and impairs oxygen delivery and uptake, Crit. Care Med. 40 (2012) 2858-2866.

15: A.S. Slutsky, Mechanical ventilation. American College of Chest Physicians' Consensus Conference, Chest. 1993: 104:1833.

16: D.C. Chao, D.J. Scheinhorn, Weaning from mechanical ventilation, Crit. Care Clin. 14; 1998:799-817. 
Table 1: Risk factor in study population.

\begin{tabular}{|l|l|l|}
\hline DM & N & $\%$ \\
\hline Present & 6 & $20.0 \%$ \\
\hline Absent & 24 & $80.0 \%$ \\
\hline HTN & 7 & $23.3 \%$ \\
\hline Present & \multicolumn{3}{|l|}{} \\
\hline Absent & 23 & $76.7 \%$ \\
\hline Smoking & \multicolumn{2}{|l}{} \\
\hline Smoker & 13 & $43.3 \%$ \\
\hline Non-smoker & 17 & $56.7 \%$ \\
\hline
\end{tabular}

Table2: Classification of patients in our study as regarding weaning outcome.

\begin{tabular}{|l|l|l||}
\hline Variant & No. & $\%$ \\
\hline Successful weaning & 17 & 56.6 \\
\hline Failed weaning & 13 & 43.3 \\
\hline
\end{tabular}

Table 3: The relation between total cycle duration and inspiration during weaning trial.

\begin{tabular}{|l|l|l|l|}
\hline Variable & Outcome & \multicolumn{2}{|l|}{ During weaning trial } \\
\cline { 3 - 4 } & & Mean & SD \\
\hline Total cycle duration & Successful weaning & 2.5 & 0.3 \\
\hline
\end{tabular}




\begin{tabular}{|c|c|c|c|}
\hline \multirow{3}{*}{\begin{tabular}{|l|} 
\\
Inspiration duration
\end{tabular}} & Failed weaning & 2.3 & 0.6 \\
\hline & P-value & \multicolumn{2}{|c|}{0.202} \\
\hline & Successful weaning & 0.9 & 0.2 \\
\hline & Failed weaning & 0.8 & 0.3 \\
\hline & P-value & \multicolumn{2}{|c|}{0.526} \\
\hline
\end{tabular}

Table 4: The relation between ABG readings in successful weaning and failed weaning group during weaning.

\begin{tabular}{|c|c|c|c|}
\hline \multirow[t]{2}{*}{ Variable } & \multirow[t]{2}{*}{ Outcome } & \multicolumn{2}{|c|}{ During weaning } \\
\hline & & Mean & SD \\
\hline \multirow[t]{3}{*}{ PH } & Successful weaning & 7.4 & 0.1 \\
\hline & Failed weaning & 7.4 & 0.1 \\
\hline & P-value & \multicolumn{2}{|l|}{0.605} \\
\hline \multirow[t]{3}{*}{$\mathrm{PCO} 2$} & Successful weaning & 48.1 & 10.7 \\
\hline & Failed weaning & 37.3 & 6.9 \\
\hline & P-value & \multicolumn{2}{|l|}{0.005} \\
\hline \multirow[t]{3}{*}{ PO2 } & Successful weaning & 111.2 & 47.1 \\
\hline & Failed weaning & 99.8 & 43.5 \\
\hline & P-value & \multicolumn{2}{|l|}{0.506} \\
\hline \multirow[t]{3}{*}{$\mathrm{HCO3}$} & Successful weaning & 37.4 & 25.3 \\
\hline & Failed weaning & 25.5 & 6.3 \\
\hline & P-value & \multicolumn{2}{|l|}{0.126} \\
\hline
\end{tabular}




\begin{tabular}{||l|l|l|l|}
\hline SO2 & Successful weaning & 96.8 & 3.2 \\
\cline { 2 - 4 } & Failed weaning & 96.9 & 2.2 \\
\cline { 2 - 4 } & P-value & 0.931 & \multicolumn{2}{|l|}{} \\
\hline \multirow{4}{*}{ R.R } & Successful weaning & 24.2 & 2.9 \\
\cline { 2 - 4 } & Failed weaning & 27.3 & 5.9 \\
\cline { 2 - 4 } & P-value & 0.115 & \multicolumn{2}{|l|}{} \\
\hline H.R & Successful weaning & 91.3 & 14.5 \\
\cline { 2 - 4 } & Failed weaning & 93.7 & 14.4 \\
\cline { 2 - 4 } & P-value & 0.661 & \multicolumn{2}{|l|}{} \\
\hline
\end{tabular}

Figure 1: The relation between number of days on ventilator before weaning and weaning time within successful weaning and failed weaning group.

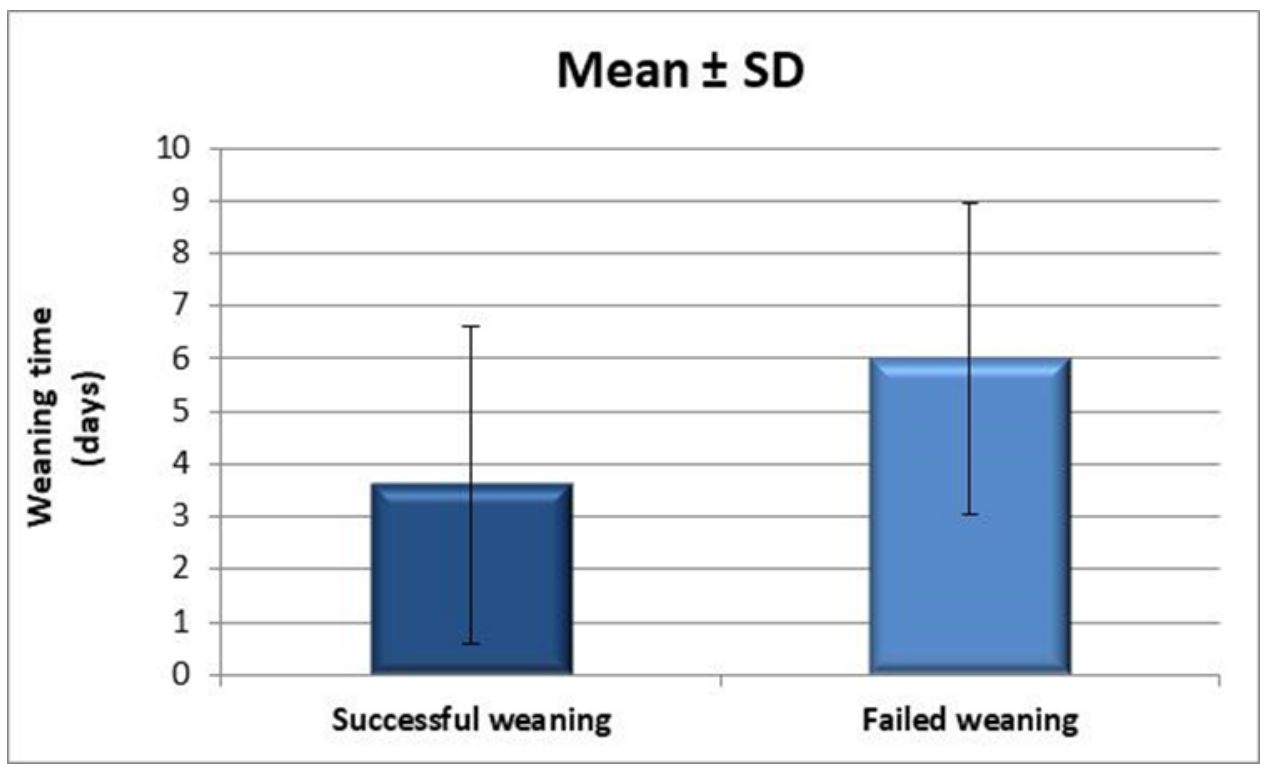

Page 84 
Figure 2: The relation between successful weaning group and failed weaning group as regards $\mathrm{TV}$ at zero day of intubation and during weaning trial.

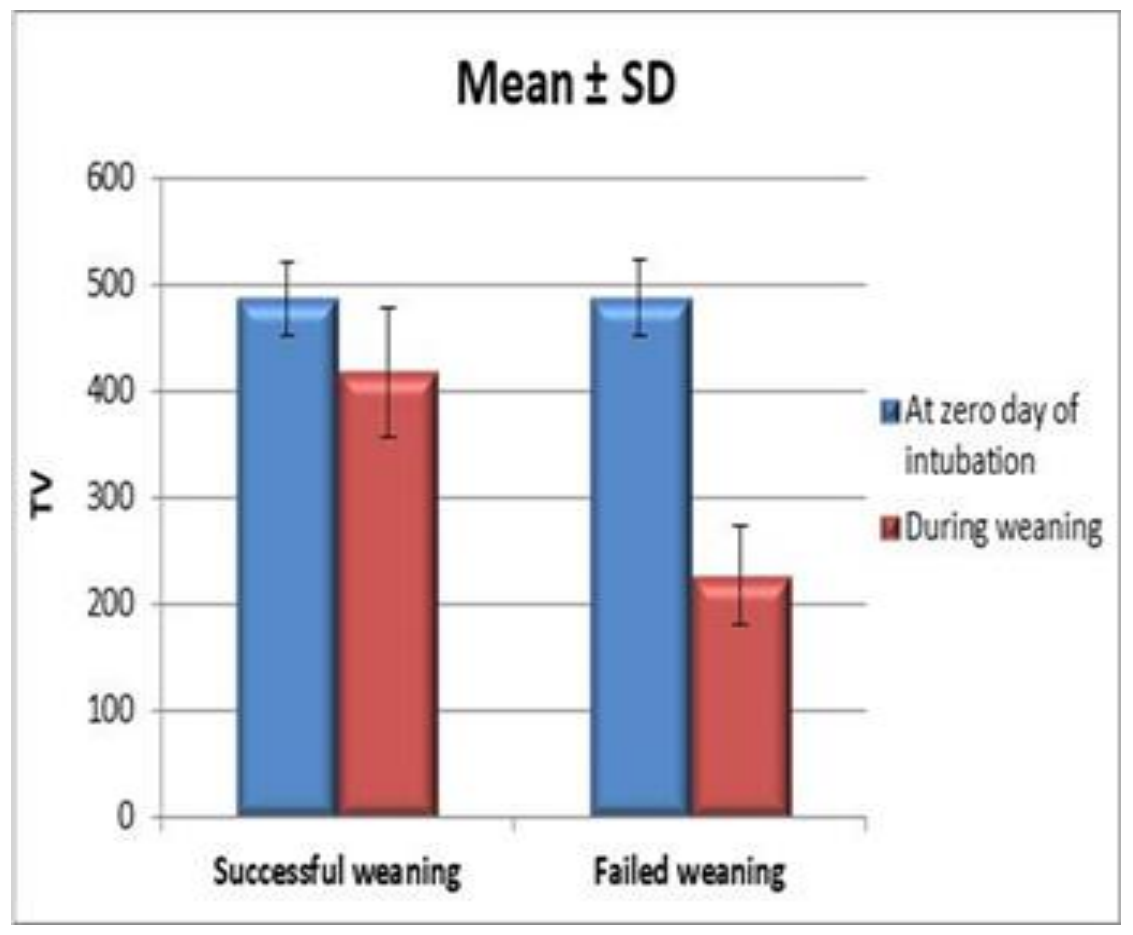

Figure 3: The relation in RSBI between successive measures during mechanical ventilation. 


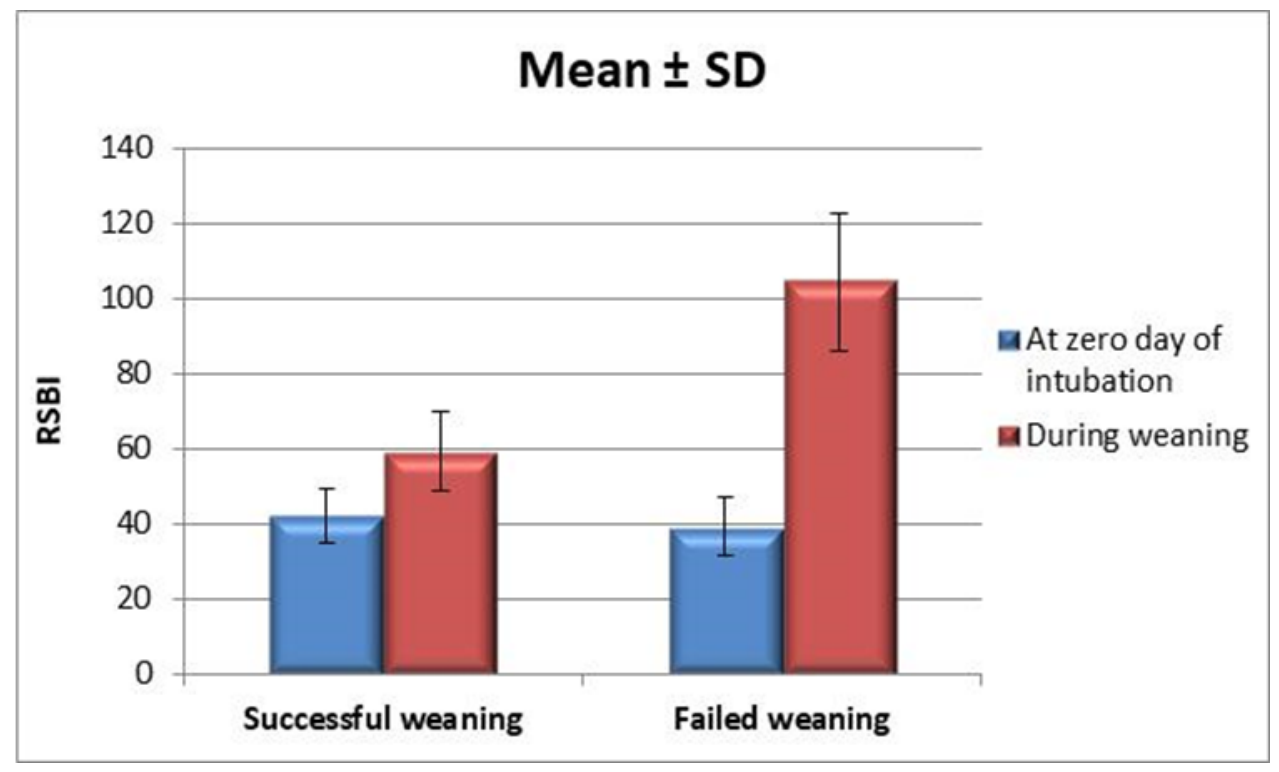

Figure 4: The relation between successful weaning group and failed weaning group as regards peak at first day of intubation and during weaning trial.

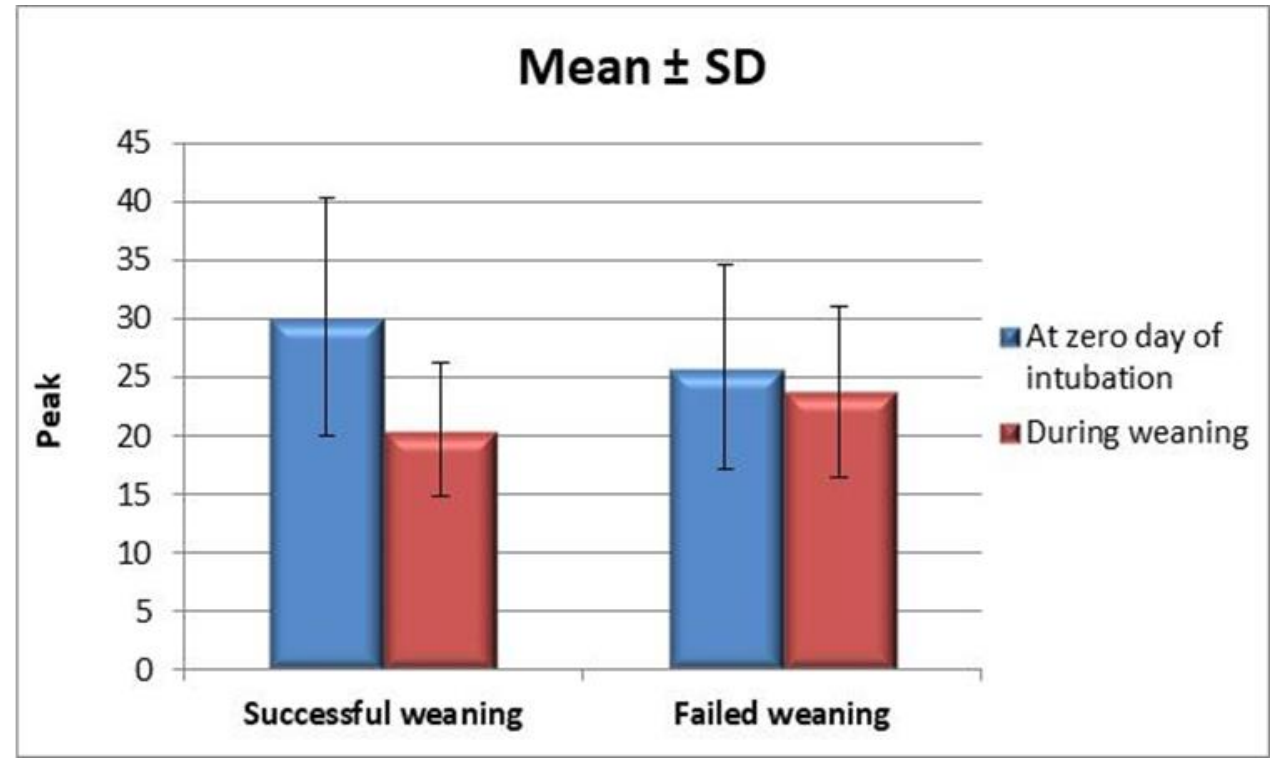


Figure 5: The relation between successful weaning group and failed weaning group as regards PCO2 during weaning trial.

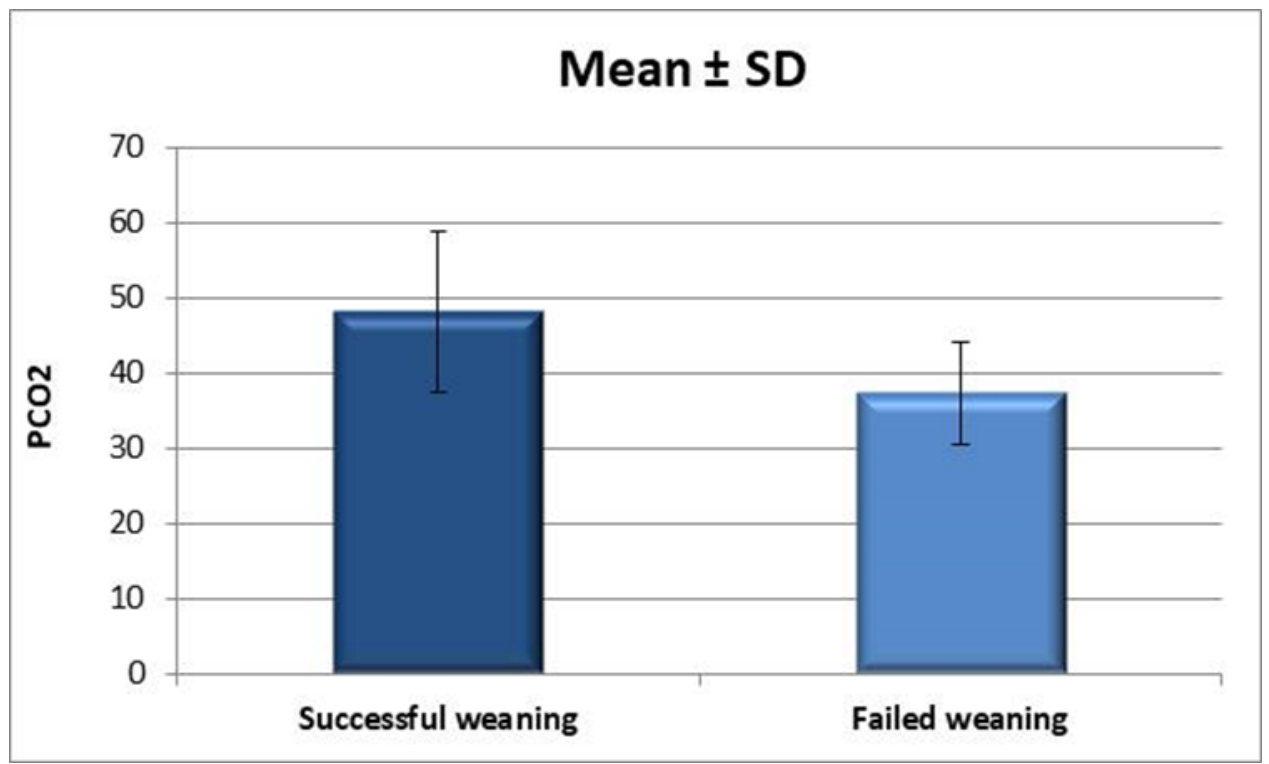

